\title{
An evaluation of completeness of tuberculosis notification in the United Kingdom
}

\author{
Jayshree Pillaye*1 and Aileen Clarke ${ }^{2}$
}

Address: ${ }^{1}$ Division of Public Health Medicine, Brent Primary Care Trust, London, UK and ${ }^{2}$ London School of Hygiene and Tropical Medicine, UK

Email: Jayshree Pillaye* - jayshree@ doctors.net.uk; Aileen Clarke - Aileen.Clarke@lshtm.ac.uk

* Corresponding author

Published: 06 October 2003

BMC Public Health 2003, 3:31
Received: 08 April 2003

Accepted: 06 October 2003

This article is available from: http://www.biomedcentral.com/|47|-2458/3/3 I

(C) 2003 Pillaye and Clarke; licensee BioMed Central Ltd. This is an Open Access article: verbatim copying and redistribution of this article are permitted in all media for any purpose, provided this notice is preserved along with the article's original URL.

\begin{abstract}
Background: There has been a resurgence of tuberculosis worldwide, mainly in developing countries but also affecting the United Kingdom (UK), and other Western countries. The control of tuberculosis is dependent on early identification of cases and timely notification to public health departments to ensure appropriate treatment of cases and screening of contacts. Tuberculosis is compulsorily notifiable in the UK, and the doctor making or suspecting the diagnosis is legally responsible for notification. There is evidence of under-reporting of tuberculosis. This has implications for the control of tuberculosis as a disproportionate number of people who become infected are the most vulnerable in society, and are less likely to be identified and notified to the public health system. These include the poor, the homeless, refugees and ethnic minorities.
\end{abstract}

Method: This study was a critical literature review on completeness of tuberculosis notification within the UK National Health Service (NHS) context. The review also identified data sources associated with reporting completeness and assessed whether studies corrected for undercount using capture-recapture $(C R)$ methodology. Studies were included if they assessed completeness of tuberculosis notification quantitatively. The outcome measure used was notification completeness expressed between $0 \%$ and $100 \%$ of a defined denominator, or in numbers not notified where the denominator was unknown.

Results: Seven studies that met the inclusion and exclusion criteria were identified through electronic and manual search of published and unpublished literature. One study used CR methodology. Analysis of the seven studies showed that undernotification varied from $7 \%$ to $27 \%$ in studies that had a denominator; and 38\%-49\% extra cases were identified in studies which examined specific data sources like pathology reports or prescriptions for anti-tuberculosis drugs. Cases notified were more likely to have positive microbiology than cases not notified which were more likely to have positive histopathology or be surgical in-patients. Collation of prescription data of two or more anti-tuberculosis drugs increases case ascertainment of tuberculosis.

Conclusion: The reporting of tuberculosis is incomplete in the UK, although notification is a statutory requirement. Undernotification leads to an underestimation of the disease burden and hinders implementation of appropriate prevention and control strategies. The notification system 
needs to be strengthened to include education and training of all sub-specialities involved in diagnosis and treatment of tuberculosis.

\section{Background}

Tuberculosis is the commonest infective disease in adults world-wide [1] with an estimated 7-8 million new cases and 2-3 million deaths occurring annually in the world [2]. The World Health Organisation (WHO) declared tuberculosis a global Emergency in 1993 because of the worldwide increase in incidence of the disease [3]. The control of tuberculosis is dependent on early identification of cases and timely notification to public health departments to ensure appropriate treatment of cases and contacts. Appropriate antimicrobial chemotherapy reduces infectivity within two weeks.

Surveillance is an important public health function in the prevention and control of diseases. Accurate, complete and timely information improves the quality of surveillance data and supports public health decision-making $[4,5]$. Prompt notification to the public health system is an important component of the surveillance process and achieves the following public health objectives: it identifies people needing follow-up to ensure that treatment is completed, and enables contact tracing and screening of close contacts. It also provides data to measure disease burden, monitor epidemiological trends, detect outbreaks, and plan and target preventative and treatment services.

There is strong evidence that there is under-notification of tuberculosis [6-8]. Cases not notified to the public health system have a higher risk of morbidity and mortality and an increased risk of multi-drug resistant tuberculosis (MDRTB) as the result of sub-optimal treatment $[9,10]$. Contacts of unnotified cases are also at risk if they are not screened and treated appropriately for active or latent disease.

Undernotification also leads to an underestimation of the disease burden. This hinders implementation of appropriate prevention and control strategies as a disproportionate number of people who become infected are the most vulnerable in society, and are also groups less likely to be notified. These include the poor, the homeless, refugees and ethnic minorities $[11,12]$.

The advent of AIDS and re-emergence of tuberculosis prompted the strengthening of surveillance networks in the UK to detect, control, and reduce these diseases. Tuberculosis is compulsorily notifiable under the Public Health (Control of Disease) Act 1984 and Public Health (Infectious Diseases) Regulation of 1988 [13,14]. The doctor making or suspecting the diagnosis is legally responsible for notification to the local "proper officer" forthwith about any patient within the local authority whom they are attending and is known or suspected of to be suffering from tuberculosis. This includes notification of both respiratory and non-respiratory forms of tuberculosis, and those cases where a decision is made to commence treatment. The proper officer should be informed of the name, age, sex and address of the premise where patient resides. The proper officer who receives the certificates should inform the appropriate Health Authority within 48 hours $[15,16]$. The proper officer is legally obliged to report to the Communicable Disease Surveillance Centre (CDSC) weekly totals of infections, followed by a monthly summary sheet. This data is entered into the Statutory Notification of Infectious Diseases (NOIDS) Database.

Several studies have evaluated the completeness of tuberculosis notification over a defined period and within particular geographical areas [17-21]. Undercount is a problem because the number of cases missed is not known. By using multiple data sources and capture-recapture (CR) methodology the number of cases that could have been missed by any of the sources is estimated [2224]. CR merges two or more sources that have identifiers like name, hospital number and date of birth. Each source list is then used as a "trapping sample", and the identifiers are used to match and link cases between data sources. Using overlap information and statistical techniques the number of cases present in the population but not identified in any of the data sets is estimated. CR is also referred to as underascertainment corrected method [25]. This estimate is more accurate and provides robust baseline data for future comparisons.

This study was part of a larger study to evaluate the undernotification of tuberculosis in the London borough of Brent.

\section{Aim}

To describe completeness of tuberculosis notification in the UK based on previous evaluation findings.

\section{Objective}

To identify data sources that may augment provider-based tuberculosis notification and to make recommendations to improve the tuberculosis notification system. 


\section{Methods \\ Search Methodology}

A systematic search of electronic bibliographic databases was carried out using MEDLINE, Cumulative Index to Nursing and Allied Health (CINAHL), Excerpta Medica Database (EMBASE), Health Management Information Consortium (HMIC) and The Cochrane Library. Searches were limited to English language, human studies and years 1966-2002. The following Medical Subject Headings (MeSH) were used: Tuberculosis, notification, reporting, surveillance, capture-recapture, multiple source and evaluation.

Several query combinations were used using the MeSH terms. A secondary search was conducted by reviewing references quoted in these papers. A manual search of review articles, editorials, and relevant Government Papers was undertaken. Studies were included if they were undertaken in a UK NHS context, assessed completeness of tuberculosis notification quantitatively, and if they evaluated completeness of tuberculosis notification by comparing the number of reports obtained through statutory or conventional reporting systems with the total number of reports estimated through one or more additional data sources. Studies were rejected if they were limited to notification of HIV co-infection or limited to assessing the quality of notification data.

\section{Outcome Measures}

The outcome measure used was notification completeness expressed between $0 \%$ and $100 \%$ of a defined denominator, or in numbers not notified where the denominator was unknown.

\section{Results \\ Results of Search}

Seven studies that met the inclusion and exclusion criteria were identified through electronic and manual searches $[17,18,22,26-29]$. One of the seven studies was identified which used CR [22].

\section{Framework for Critical Appraisal}

A framework to critically appraise the selected articles was devised by using the updated guidelines from the CDC for Evaluating Public Health Surveillance Systems [30] and adapting the format used by Doyle et al [25].

Information obtained from each study is shown in Box 1 - Additional file: 1 . Descriptions of each study and author details are recorded in the first column. The supplemental data sources used for case ascertainment are noted in column two. The number of cases ascertained by each data source was not included, as cases would be identified by more than one data source. The third column records the number (\%) notified to the statutory reporting system. In order to define a notification rate both a numerator and denominator are required. The numerator is the number of cases that are notified and the denominator is the total number of cases ascertained through use of supplemental data sources. A rate may be over or under-estimated for example if the denominator were artificially small or large because the numerator and denominator are not drawn from the same source.

The penultimate column represents the study authors' comments and recommendations. The strengths and limitations of the data quality are discussed in the last column. Verification of diagnosis by examining case notes and pathology reports improved the quality of the data. Better estimates of notification were obtained when the statutory notifications and supplementary data sources covered the same catchment area and same time periods. Using data sources that included patients treated in hospitals and in the community would have increased case ascertainment.

Information was also abstracted on whether cases were matched and linked between the data sources. This would have facilitated the use of capture-recapture (CR) methodology.

All seven studies were graded as Level IV evidence [31].

\section{Summary of main findings}

Analysis of the seven studies showed that notification of tuberculosis in the UK is incomplete, although it is a statutory requirement. Undernotification varied from $7 \%$ to $27 \%$ in studies that had a denominator, and $38-49 \%$ of extra cases were identified that were not notified in studies which looked at specific data sources like pathology reports and prescriptions for anti-tuberculosis drugs. No single data source was found to measure the burden of tuberculosis effectively. Cases notified were more likely to have had positive microbiology than cases not notified which were more likely to have had positive histopathology or had been surgical in-patients. Using multiple data sources including prescription data (dispensing of two or more anti-tuberculosis drugs) increased case ascertainment. However cases treated for chemoprophylaxis need to be excluded when using prescription data. Only one study was population based [29].

Use of CR can correct for undetected cases and provides a better estimate of undernotification. Two studies [18,27] which matched and linked identifiers between the data sources could have used CR but did not, while one study [29] could not use this method because the principles of CR were violated, as stated in Box 1.

The main issues with these studies were: 
- Accuracy of diagnosis was not verified in all studies. Verification was increased when case notes were matched with microbiological or histopathological reports

- Lack of clarification whether statutory notification and supplemental data sources covered the same catchment area might have compromised the undernotification estimate

- Ascertainment of cases was limited mainly to hospital patients although patients are treated at other settings. This missed patients treated in primary care, and those that are more likely not to be notified e.g. those treated out of the borough, mobile and disadvantaged groups (homeless and undocumented persons).

\section{Discussion and Conclusions}

The review identified gaps in information on evaluation of completeness of tuberculosis notification within the NHS context. I identified no previous review of studies on completeness of tuberculosis notification, although evidence based methods are now standard tools to assess the effectiveness of health care interventions, including public health surveillance systems $[32,33]$,. Also, tuberculosis is a well-researched clinical topic and a national and global public health problem. Reasons for this include the lack of accepted frameworks for appraising research into public health interventions and the difficulties in using established methods [33]. The basic tenets of evidence-based methods require criteria that can be used to evaluate the strengths, limitations and gaps in studies; and to determine whether they provide credible and useful information.

The body of evidence has shown that that there is undernotification of tuberculosis and an underestimation of the burden of disease. Evaluation of completeness of notification misses cases that are less likely to be notified, like the homeless and mobile populations who are more likely to require targeted services to improve prevention and control of tuberculosis. Also, correction for undercount using CR is now an accepted method in human epidemiology [34]. Using multiple data sources and CR methodology allows for variables that can influence reporting patterns for the different sources [24,35]. Only one study [22] used this method.

Notwithstanding the limitations discussed, this review identified data sources that are potentially good sources of surveillance information and the NHS should routinely access these data sources to improve tuberculosis surveillance and case finding.
In the light of the findings, the following recommendations are made to increase the notification of tuberculosis and to "capture" disadvantaged groups:

- The reporting from all sub-specialities involved in tuberculosis investigation and treatment should be centralised and co-ordinated by the local Consultant in Communicable Disease Control

- Histological specimens should be collected separately for mycobacterium culture to increase accuracy of diagnosis. Surgeons should be trained on collection of such specimens and educated about the importance of notification of infectious diseases

- Anti-tuberculosis prescriptions should be collated when anti-tuberculosis drugs are dispensed and notification by pharmacists should be explored

- Further research is required to identify the minimum data sources required to evaluate tuberculosis notification using $\mathrm{CR}$, and on statistical techniques to correct for interdependence between data sources. Figures based on undernotification alone may underestimate the level of disease burden, and through variations in notification patterns can also distort observed trends.

\section{Competing Interests}

None declared.

\section{Author's Contribution}

JP conceived of the study and undertook the literature search. AC contributed to the design and framework. Both authors read and approved the final manuscript

\section{Additional material}

\section{Additional file 1}

Click here for file [http://www.biomedcentral.com/content/supplementary/14712458-3-31-S1.doc]

\section{References}

I. World Bank: World Development Report 1993. Washington. The World Bank 1993.

2. Raviglone MC: The TB epidemic from 1992 to 2002. Proceedings from the $4^{\text {th }}$ World Congress on Tuberculosis. Tuberculosis 2003, 83:4-14.

3. WHO: WHO declares tuberculosis a global emergency (press release). WHO/3I. 4-23-1993. Geneva 1993.

4. Langmuir AD: The surveillance of communicable diseases of national importance. N Engl J Med 1963, 268:|82-91.

5. Bloch $A B$ et al.: The Need for Epidemic Intelligence. Public Health Reports 1996, III:26-31. 
6. Van Buynder P: Enhanced surveillance of tuberculosis in England and Wales: circling the wagon? Communicable disease and public health 1998, 1:219-20.

7. Njoo H: National surveillance: a Canadian perspective. International Journal of Tuberculosis and Lung Disease 2000, 4:SI39-SI 45.

8. Van Loenhout-Rooyackers JH, Leufkens HGM, Hekster YA and Kalisvaart NA: Pyrazinamide use as a method of estimating underreporting of tuberculosis. Int J of Tuberc Lung Dis 200I, 5(12): $1156-1160$

9. World Health Organisation: Anti-tuberculosis drug resistance in the world: the WHO/IUTLD global project on anti-tuberculosis drug resistance surveillance 1994-7. Geneva, WHO 1997.

10. Farmer P and Kim JY: Community based approaches to the control of multidrug resistant tuberculosis: introducing "DOTSplus". BM] I 998, 3 | 7:67|-4.

II. Interdepartmental Working Group on Tuberculosis: The Prevention and Control of Tuberculosis in the United Kingdom: Recommendations for the control and prevention of tuberculosis at local level. Department of Health and Welsh office 1996.

12. Hayward A: Tuberculosis control in London: the need for change. A report for the Thames Regional Directors of Public Health (discussion document). London: NHS Executive 1998.

13. HMSO: The Public Health (Control of Diseases) Act. Crown Copyright 1984

14. HMSO: The Public Health (Infectious Diseases) Regulations. Crown Copyright 1988.

15. McEvoy M and Maguire $\mathrm{H}$ : Tuberculosis in London: a review, and an account of the work of the London Consultants in Communicable Disease Control Group Working Party. Journal of Hospital Infection 1995, 30(Suppl):296-305.

16. McCormick A: The notification of infectious diseases in England and Wales. Communicable Disease Report Review 1993 3:RI9-R25

17. Sheldon CD, King K, Cock H, Wilkinson P and Barnes NC: Notification of tuberculosis: how many cases are never reported? Thorax 1992, 47: 1015-8.

18. Mukerjee AK: Ascertainment of non-respiratory tuberculosis in five boroughs by comparison of multiple data source. Communicable Disease and Public Health 1999, 2: 143-4.

19. Washko RM and Frieden TR: Tuberculosis surveillance using death certificate data, New York City, 1992. Public Health Reports 1996, II(3):25I-5.

20. Migliori GB, Spanevello A, Ballardini L, Neri M, Gambarini C and Moro ML et al.: Validation of the surveillance system for new cases of tuberculosis in a province of northern Italy. Varese Tuberculosis Study Group. European Respiratory Journal 1995, 8:1252-8.

21. Menon A and Heydon J: Undernotification of tuberculosis in Otago:national Implication. NZ Med J 1995, 108,955:80-82.

22. Tocque $\mathrm{K}$, Bellis MA, Beeching NJ and Davies PDO: Capture recapture as a method of determining the completeness of tuberculosis notifications. Communicable Disease and Public Health 200I, 4:|4|-3.

23. Morse T, Dillon C, Warren N, Hall C and Hovey D: CaptureRecapture estimation of unreported work-related mucoskeletal disorders in Connecticut. American Journal of Industrial Medicine 200I, 39:636-42.

24. Nanan DJ and White F: Capture-recapture: reconnaissance of a demographic technique in Epidemiology. Chronic Diseases in Canada 1997, 18(4): [http://www.hc-sc.gc.ca/pphb-dgspsp/publicat/ cdic-mcc/l8-4/a e.html].

25. Doyle TJ, Glynn MK and Groseclose : Completeness of Notifiable Infectious Disease reporting in the United States : An Analytic Literature Review. Am J of Epidemiol 2002, I 55:866-74.

26. Brown JS, Wells F, Barnes NC, Duckworth G and Paul EA: Improving notification rates for tuberculosis. $B M$ J 1995, 3 I 0:974.

27. Grove A, Valentine J, MacDonald T, Roworth M and Winter J: The ascertainment and management of tuberculosis in Tayside, Scotland during 1993-4. 59. Health Bulletin 200I, 59(4): [http:// www.scotland.gov.uk/deleted//health/cmobulletin/hb594-06.asp].

28. Bradley BL, Kerr KM, Leitch AD and Lamb D: Notification of tuberculosis: can the pathologist help? BM] 1988, 297:595.

29. Devine MJ and Aston R: Assessing the completeness of tuberculosis notification in a health district. Communicable Disease Report 1995, 5:RI37-R|40.
30. Updated Guidelines for Evaluating Public health Surveillance Systems [http://www.cdc.gov/mmwr/preview/mmwrhtml/ rr50I3al.htm]

31. Guyatt GH, Sinclair JC, Hayward R and Cook JC: Evidence-Based Medicine Working Group Users' Guides to Evidence-Based Practice: Method for Grading Health Care Recommendations. [http://www.cche.net].

32. Ray JG: Evidence in Upheaval: Incorporating Observational Data into Clinical Practice. Arch Intern Med 2002, 162:249-54.

33. Rychenik $L$ and Frommer M: A Schema for evaluating evidence on Public Health Interventions. Version 4. National Public Health Partnership, Melbourne 2002.

34. McCarty DJ, Tull ES, Moy CS, Kwoh CK and Laporte RE: Ascertainment Corrected Rates: Applications of Capture-Recapture Methods. International Journal of Epidemiology 1993, 22:559-65.

35. Papoz L, Blakau B and Lellouch J: Case counting in Epidemiology: Limitations on methods based on multiple data sources. International Journal of Epidemiology 1996, 25:474-8.

\section{Pre-publication history}

The pre-publication history for this paper can be accessed here:

http://www.biomedcentral.com/1471-2458/3/31/prepub
Publish with Biomed Central and every scientist can read your work free of charge

"BioMed Central will be the most significant development for disseminating the results of biomedical research in our lifetime. "

Sir Paul Nurse, Cancer Research UK

Your research papers will be:

- available free of charge to the entire biomedical community

- peer reviewed and published immediately upon acceptance

- cited in PubMed and archived on PubMed Central

- yours - you keep the copyright
BioMedcentral 